\title{
Kontribusi Atraksi Wisata Arung Jeram Terhadap Masyarakat Lokal Di Desa Pekraman Kedewatan Kecamatan Ubud, Kabupaten Gianyar
}

I Wayan Dedy Karnawan a,1, I Gusti Agung Oka Mahagangga a, 2

1.wayandidink14@gmail.com.com,20kamahagangga@unud.ac.id

a Program Studi S1 Destinasi Pariwisata, Fakultas Pariwisata,Universitas Udayana, Jl. Dr. R. Goris, Denpasar, Bali 80232 Indonesia

\section{Abstract}

The existence of a tourist attraction required improving the welfare of the surrounding community. This study aims to find out how many contributions of rafting tourist attraction in society Kedewatan village, in order to contribute positively to the welfare of local communities. Therefore, this research is expected to provide benefits to related parties.

This research used of primary data and secondary data sources, while the type of data used quantitative and qualitative data. Data were collected through observation, interview and literature study. Determination of informants in this research used purposive sampling technique. The data analysis used is qualitative data analysis techniques and restricted by contribution concept, the concept of community participation, and the concept of community-based tourism.

The results obtained are the company's contribution to Kedewatan society been running smoothly, which contributes to the Kedewatan village in the form of donations which pay each month, contributing directly to the public in the form of add job vacancies for local people, contributing indirectly to the local communities that helping local community businesses. To optimizie job vacancies for local communities, it is necessary to co-operation between companies and Kedewatan communities in recruitment labor.

Keywords: Contributions, rafting, Kedewatan village community

\section{PENDAHULUAN}

Pesatnya perkembangan pariwisata Bali dapat dilihat dari peningkatan kunjungan wisatawan ke Bali yaitu di bulan Desember 2015 naik sebesar $6,70 \%$, sedangkan di bulan Desember 2014 sebesar naik 36,80\% dari tahun sebelumnya (BPS Provinsi Bali, 2016), tentunya hal tersebut tidak terlepas dari adanya kebudayaan, kesenian, serta keindahan alam Bali yang mempesona, merupakan keunggulan daya tarik wisata yang dimiliki Bali untuk menunjang kepariwisataan dari daerah lainnya.

Peran serta masyarakat dengan pemerintah dan stakeholder dalam perkembangan pariwisata merupakan komponen penting yang berjalan selalu harus berdampingan agar tidak menguntungkan salah satu pihak.

Seni dan budaya, serta kehidupan masyarakat lokal yang mendominasi daerah Ubud menjadi daya tarik wisatawan untuk berkunjung, ini terlihat dari banyaknya wisatawan yang datang dan tinggal di area Ubud. Aliran sungai ayung yang membatasi Ubud dengan daerah lainnya dapat dimanfaatkan dengan baik untuk dijadikan atraksi wisata arung jeram. Banyaknya permintaan wisatawan dalam melakukan atraksi arung jeram membuat para pemilik modal memanfaatkan peluang untuk mendirikan perusahaan arum jeram. Desa Pekraman Kedewatan, Kecamatan Ubud merupakan sasaran pemilik modal untuk membangun perusahaan arum jeram. Sampai saat ini terdapat 8 perusahaan arum jeram yang berkembang di Desa Pekraman Kedewatan, KecamatanUbud.

Keberadaan suatu atraksi wisata dituntut dapat mensejahterakan masyarakat sekitar, dimana atraksi wisata tersebut dibangun, supaya pertumbuhan perekonomian masyarakat merata dan mampu meretas kemiskinan terutama masyarakat yang berada di pulau Bali khususnya di Desa Kedewatan, Ubud.

Berdasarkan latar belakang diatas maka rumusan masalah yang diangkat adalah "Apa kontribusi atraksi wisata arung jeram terhadap masyarakat lokal di Desa Pekraman Kedewatan, Kecamatan Ubud, Kabupaten Gianyar?". Tujuan penulisan jurnal ini adalah untuk mengetahui kontribusi atraksi wisata arung jeram terhadap masyarakat lokal di Desa Pekraman Kedewatan, Kecamatan Ubud, Kabupaten Gianyar. 


\section{KEPUSTAKAAN}

\subsection{Tinjauan Penelitian Sebelumnya}

Tinjauan penelitian yang digunakan dalam penelitian ini yaitu skripsi pertama menguraikan tentang sumbangan yang dapat diberikan oleh seni pertunjukkan kecak fire terhadap kesejahteraan senimannya (penari dan penabuh) yang ditinjau dari segi ekonomi yaitu besarnya pendapatan yang diperoleh, serta dari segi sosial dan budaya meliputi aspek pendidikan, aspek upacara serta aspek psikologi (Inten,2006).

Skripsi yang kedua, yaitu menguraikan tentang kontribusi yang dirasakan masyarakat baik di bidang ekonomi, bidang sosial yang terdiri dari aspek pendidikan, aspek upacara/agama, dan aspek seni budaya yang berpengaruh besar bagi kesejahteraan masyarakat (Suarmana,2014).

Dalam penelitian ini menggunakan beberapa konsep, antara lain tinjauan tentang konsep Kontribusi adalah sejumlah iuran sumbangan kepada perkumpulan dan sebagainya. Bentuk kontribusi pariwisata dari segi ekonomi ditinjau dari dua segi yaitu : pertama kontribusi langsung dan kontribusi tidak langsung yang ditimbulkan oleh kegiatan langsung pariwisata (Soehasto, dalam Suparno 2008). Konsep kontribusi dalam penelitian ini untuk mengetahui bentuk-bentuk kontribusi perusahaan atraksi wisata arung jeram terhadap masyarakat dan Desa Pekraman Kedewatan baik kontribusi yang diperoleh secara langsung maupun tidak langsung yang dapat mempengaruhi kesejahteraan masyarakat lokal.

Konsep Pariwisata Berbasis Masyarakat konsep ini harus memperhatikan keterlibatan masyarakat lokal yang merupakan syarat mutlak untuk tecapainya pembangunan pariwisata yang berkelanjutan(Pitana, 2002). Konsep pariwisata berbasis masyyarakat dalam penelitian ini untuk mengetahui seberapa besar keterlibatan masyarakat Desa pekraman Kedewatan di suatu perusahaan rafting.

Konsep Partisipasi Masyarakat yaitu dalam proses pengembangan pariwisata, partisipasi masyarakat dapat dibedakan menjadi dua jenis yaitu, yang pertama partisipasi langsung dan partisipasi tidak langsung (Prayogo, dalam Christiani, 2013). Konsep partisipasi masyarakat dalam penelitian ini untuk mengetahui jenis partisipasi masyarakat Desa Pekraman Kedewatan di suatu perusahaan rafting.

Konsep tentang Desa Pekraman adalah Secara formal Desa Pekraman dimuat dalam Peraturan Daerah Provinsi Bali No 3 tahun 2001 tentang Desa Pekraman. Desa Pekraman yakni "kesatuan masyarakat hukum adat di provinsi Bali yang mempunyai satu kesatuan tradisi dan tata karma pergaulan hidup masyrakat umat hindu secara tutun temurun dalam ikatan Tri Kahyangan Desa yang mempunyai wilayah tertentu dan harta kekayaan sendiri serta berhak mengurus rumah tangganya sendiri. Konsep Desa Pekraman ini untuk menjelaskan ruang lingkup Desa Pekraman, dalam penelitian mengambil Desa Pekraman Kedewatan.

Konsep Daya Tarik Wisata adalah suatu usaha yang menyelenggarakan pertunjukkan olah raga, pameran atau promosi dan harus ditempat tertutup atau tempat yang terbuka yang bersifat komersial atau tidak, namun dapat menarik atau ditujukan untuk menarik para wisatawan untuk dikunjungi, disaksikan, dan dinikmati baik yang dikelola oleh orang pribadi atau badan usah. (Yoeti, 1982). Konsep daya tarik ini adalah untuk menjelaskan bahwa atraksi wisata arung jeram merupakan sebuah daya tarik wisata.

\section{RUANG LINGKUP}

Memperjelas mengenai batasan-batasan kontribusi yang diperoleh masyarakat lokal Desa Pekraman Kedewatan dari perusahaan atraksi wisata arung jeram yang ada di Desa Pekraman Kedewatan. Jadi, Ruang lingkup penelitian ini yaitu :

- Kontribusi yang diperoleh dari atraksi wisata arung jeram terhadap kesejahteraan masyarakat lokal dari adanya pembangunan perusahaan atraksi wisata arung jeram di Desa Pekraman Kedewatan, baik masyarakat yang berpartisipasi langsung seperti staf pegawai atau honorer, dan yang tidak berpartisipasi langsung seperti ; pengusaha warung makan, pedagang minuman di sepanjang jalur rafting sungai Ayung, organisasi Dewata Transport dan penyedia akomodasi homestay. 
- Kontribusi dari atraksi wisata arung jeram terhadap Desa Pekraman Kedewatan. Baik itu berupa iuran wajib maupun secara sukarela

\section{METODE PENELITIAN}

\subsection{Lokasi Penelitian}

Penelitian ini mengambil batasan lokasi di atraksi wisata arung jeram yang berlokasi di Desa Pekraman Kedewatan, Kecamatan Ubud, Kabupaten Gianyar. Tepatnya berjarak $45 \mathrm{~km}$ dari Kota Denpasar. Banyaknya pembangunan perusahaan penyedia atraksi wisata arung jeram di Desa Pekraman Kedewatan sehingga dapat menarik keuntungan dari segi ekonomi sekaligus menjadi lapangan pekerjaan bagi masyarakat lokal.

\subsection{Jenis dan Sumber Data}

Jenis dan sumber data yang digunakan dalam penelitian ini yaitu : Data Kualitatif adalah data yang bersifat uraian dan bukan bernilai numerik atau bukan angka (Kusmayadi,2000). Penelitian kualitatif dalam penelitian ini adalah gambaran umum lokasi wisata arung jeram, kontribusi yang diperoleh masyarakat dari perusahaan arung jeram dan partisipasi masyarakat lokal terhadap perkembangan atraksi wisata arung jeram baik itu sebagai staf pegawai maupun penyedia fasilitas penunjang dalam kegiatan wisata arung jeram.

Data Kuantitatif adalah data yang bukan menggunakan uraian melainkan dengan menggunakan numerik atau angka (Kusmayadi,2000). Data kuantitatif dalam penelitian ini seperti jumlah masyarakat kedewatan berdasarkan pendidikannya, jumlah masyarakat lokal yang bekerja dalam perusahan wisata arum jeram.

Data primer merupakan data yang diperoleh saat turun ke lapangan dan mendapat informasi langsung mengenai permasalahan (Moleong,2004). Sumber data primer dalam penelitian ini berupa hasil wawancara mendalam kepada ke delapan pengelola perusahaan atraksi wisata arung jeram yang ada di Desa Pekraman kedewatan, kelihan Desa Pekraman Kedewatan, masyarakat lokal yang ikut berpartisipasi baik sebagai staf pegawai ataupun tidak sebagai staf dalam atraksi wisata arung jeram.
Data Sekunder yaitu data yang diperoleh dari instansi yang terkait dalam bentuk publikasi, serta laporan tahunan, company profile/profil perusahaan. (Kusmayadi,2000). Data penelitian ini berupa, brosur dari perusahaan arum jeram, website BPS Bali seperti jumlah kunjungan wisatawan ke Bali.

\subsection{Teknik Pengumpulan Data}

Teknik pengumpulan data yang digunakan dalam penelitian ini, antara lain :

1. Observasi adalah mengumpulkan data dengan cara meneliti langsung mengamati, atau melihat kejadian yang sedang berlangsung (Kusmayadi,2000). Teknik ini dilakukan dengan obeservasi langsung ke lapangan untuk mendapatkan gambaran yang jelas mengenai wisata arung jeram, gambaran umum lokasi penelitian, partisipasi masyarakat terhadap wisata arung jeram.

2. Wawancara yaitu menggali informasi dengan berinteraksi dan melakukan wawancara kepada informan (Kusmayadi,2000). Teknik pengumpulan data dalam penelitian ini seperti, kontribusi yang diperoleh masyarakat Desa Pekraman Kedewatan terhadap keberadaan atraksi wisata arung jeram, partisipasi masyarakat baik itu sebagai staf pegawai maupun penyedia fasilitas pendukung dalam atraksi wisata arung jeram.

3. Studi kepustakaan adalah berbentuk tulisan atau catatan yang berupa peristiwa, karya dari seseorang maupun gambar (Sugiyono,2013). Dalam penelitian ini dokumen yang digunakan adalah monografi desa, profil desa, jumlah staf pegawai di setiap perusahaan arung jeram, foto sungai ayung sebagai tempat dilakukan atraksi wisata arung jeram.

\subsection{Teknik Penentuan Informan}

Teknik penentuan informan dalam penelitian ini dilakukan dengan teknik purposive sampling. Purposive sampling yang dimaksud disini adalah dimana menetapkan lebih awal siapa saja yang menjadi sampelnya. (Mukhtar, 2013). Informan dalam penelitian ini antara lain : Kelihan Desa Pekraman Kedewatan, kedelapan 
pengelola perusahaan arum jeram, masyarakat lokal yang berpartisipasi sebagai staf di perusahaan arum jeram, pedagang minuman yang ada di pinggir sungai, dan pemilik akomodasi yang merupakan masyarakat lokal.

\subsection{Teknik Analisis Data}

Teknik analisis data yang digunakan dalam penelitian ini adalah teknik analisis data kualitatif dimana proses berjalan sebagai berikut : Mencatat yang menghasilkan catatan lapangan, mengumpulkan, memilah-milah, mengklarifikasikan, mensistesiskan, membuat ikhtisar, dan membuat indeksnya. (Seiddel dalam Moleong, 2012)

\section{HASIL DAN PEMBAHASAN}

\subsection{Gambaran Umum Desa Kedewatan}

Desa Kedewatan terletak membujur dari arah Utara ke Selatan, yang diapit dua buah sungai yang besar yaitu Sungai Ayung disebelah Barat dan Sungai Wos Kauhan disebelah Timur, dengan luas wilayah 474,62 Ha.

Kedua sisi Sungai tersebut telah memberikan manfaat ekonomi dan kesejahteraan yang cukup besar bagi masyarakat Desa Kedewatan dengan adanya investasi, baik investasi asing maupun lokal, di bidang sarana pariwisata seperti hotelhotel, butik, atraksi wisata. Dengan berdirinya akomodasi pariwisata memacu bertumbuh kembangnya usaha-usaha penunjang lainnya seperti warung-warung makanan dan minuman, transportasi wisata, artshop dan lain-lainnya. Banyaknya jumlah akomodasiakomodasi dan usaha penunjangnya tersebut, mampu menyerap tenaga kerja yang cukup besar baik tenaga kerja yang berasal dari Desa Kedewatan maupun dari luar Desa bahkan beberapa tenaga kerja asing juga ada terutama yang menempati posisi top manajemen. (Kantor Desa Kedewatan, 2014).

5.2 Jenis-jenis Atraksi Wisata yang ada di

\section{Desa Pekraman Kedewatan.}

Perkembangan kepariwisataan di Desa Pekraman Kedewatan yang semakin meningkat dilihat dari penyediaan fasilitas pariwisata, memacu tumbuh kembangnya penunjang atraksi wisata lainnya. Sesuai konsep Yoeti (Bab II hal 16) ada beberapa jenis atraksi wisata yang ada di Desa
Kedewatan yang kini sudah berjalan lancar yaitu : cooking class, pertunjukkan seni taritarian dan tentunya atraksi wisata Arum jeram yang sudah berkembang di desa pekraman Kedewatan.

\subsection{Kontribusi secara langsung yang diperoleh masyarakat Desa Pekraman Kedewatan dari perusahaan arung jeram}

Dari delapan perusahaan arung jeram yang ada di Desa Pekraman Kedewatan, lima pemilik perusahaan arung jeram bukan dari Desa Pekraman Kedewatan yaitu Perusahaan Sobek, Bali Adventure, Ubud Rafting, Payung Rafting, Graha Rafting. Sisanya, tiga perusahaan yaitu perusahaan Toekad Rafting, Sari Profit Rafting, Gangga Rafting pemilik perusahaan merupakan berasal dari Desa Pekraman Kedewatan. Dari delapan perusahaan rafting yang ada di Desa Pekraman Kedewatan, 81 orang merupakan pekerja staf dan 10 orang pekerja honorer yang merupakan dari masyarakat lokal Desa Pekraman Kedewatan. Berdasarkan hasil observasi sebagian besar masyarakat Desa Pekraman Kedewatan sudah memiliki pekerjaan yang tetap. Lapangan pekerjaan yang ada di Desa Pekraman Kedewatan lainnya seperti hotel, villa, dan warung makan, sudah sangat memadai dalam mengatasi pengangguran khususnya bagi masyarakat Desa Kedewatan.

Perusahaan arung jeram yang terdapat di Desa Pekraman kedewatan sudah melibatkan masyarakat lokal di dalam operasional atraksi wisata arung jeram tersebut.

5.4 Kontribusi secara tidak langsung yang diperoleh masyarakat Desa Pekraman Kedewatan dari Perusahaan Arung Jeram.

Kontribusi secara tidak langsung yang dimaksud dalam hal ini adalah masyarakat Pekraman Kedewatan yang tidak ikut bekerja dalam suatu perusahaan arung jeram, akan tetapi masyarakat dapat merasakan manfaat positif dari adanya perusahaan arung jeram tersebut. Beberapa contoh kontribusi yang secara tidak langsung dapat dirasakan oleh masyarakat lokal Kedewatan adalah :

1. Usaha Warung Makan dan Minuman

Banyaknya berdiri perusahaaan atraksi wisata arung jeram di desa kedewatan membuka peluang masyarakat kedewatan 
untuk membuka usaha warung makan dan minuman Hasil penjualan rata-rata perhari yang bisa di peroleh oleh setiap pedagang di musim high season mencapai empat ratus hingga lima ratus ribu dan di musim low season sekitar seratus lima puluh ribu.

2. Usaha Akomodasi Pondok Wisata (homestay).

Berdasarkan dari segi tingkat hunian kamar, perusahaan arung jeram hampir tidak mempengaruhi naik turunnya tingkat hunian pada setiap usaha penginapan di Desa Pekraman Kedewatan, melainkan hanya bisa mendapatkan dana tambahan apabila pengelola dapat mendaftarkan wisatawan yang menginap untuk melakukan arung jeram.

3. Organisasi Dewata Transport

Organisasi Dewata Transport di bentuk oleh beberapa masyarakat lokal yang berada dibawah naungan Desa Pekraman Kedewatan untuk melayani antar jemput wisatawan hotel, villa, rafting yang ada di Desa Pekraman Kedewatan. Jadi, banyaknya kunjungan wisatawan yang menginap di Desa Pekraman Kedewatan dan yang melakukan atraksi wisata arung jeram sangat berpengaruh terhadap perkembangan organisasi masyarakat ini.

\subsection{Kontribusi yang diperoleh Desa Pekraman Kedewatan dari perusahaan Arung Jeram}

Kontribusi yang diperoleh Desa Kedewatan dari perusahaan-perusahaan yang berdiri di Desa Kedewatan yaitu semuanya berupa uang. Hasil retribusi yang diperoleh Desa Kedewatan sebagian besar bersumber dari perusahaan rafting. Setiap perusahaan rafting yang ada di Desa Kedewatan dikenakan iuaran sebesar Rp.2.000.000 setiap bulannya. Dari 8 jumlah perusahaan rafting yang ada hanya 5 perusahaan yang wajib membayar iuran setiap bulannya, ke-5 perusahaan rafting itu adalah perusahaan Sobek Rafting, Ubud Rafting, Payung Rafting, Bali Adventure Rafting, dan Graha Rafting. Sisanya perusahaan rafting yaitu Toekad Rafting, Sari Profit Rafting, New Gangga Rafting, ketiga perusahaan ini dimiliki oleh masyarkat lokal. Ke-tiga perusahaan lokal tersebut tidak dibebankan iuran wajib setiap bulannya, tetapi ke-tiga perusahaan ini bukan berarti tidak berkontribusi, namun dalam hal iuran terhadap Desa Kedewatan ketiga perusahaan ini selalu berkontribusi langsung memberi sumbangan baik berupa uang maupun material di setiap acara desa seperti upacara piodalan, pembangunan pura, kegiatan upacara agama.

\section{PENUTUP}

\subsection{Simpulan}

Berdasarkan hasil penelitian diperoleh simpulan :

1. Kontribusi perusahaan arung jeram ke masyarakat kedewatan

a. Kontribusi secara langsung yaitu, bertambahnya lapangan pekerjaan bagi masyarakat lokal. Dari seluruh perusahaan rafting terdapat 81 orang bekerja sebagai staf dan 10 orang sebagai honorer merupakan masyarakat Desa Pekraman Kedewatan yang bekerja di seluruh perusahaan arung jeram.

b. Kontribusi secara tidak langsung yaitu, mendorong masyarakat lokal untuk membuka usaha seperti usaha warung minuman yang ada di sepanjang jalur arung jeram dan meningkatkan penjualan usaha warung makan di sekitaran perusahaan arung jeram seperti warung Ibu suna yang dulu perhari dapat menjual 75 bungkus, sekarang sampai 150 bungkus nasi.

2. Kontribusi perusahaan arung jeram ke Desa Pekraman Kedewatan

Kontribusi yang diperoleh langsung adalah dari lima perusahaan yang pemiliknya bukan dari Desa Pekraman Kedewatan berupa iuran uang sebesar Rp.2.000.000,00, dan tiga perusahaan yang pemiliknya dari Desa Pekraman Kedewatan memberikan sumbangan suka rela pada saat ada kegiatan di Desa Pekraman seperti piodalan di pura dan memperbaiki bangunan balai banjar.

\subsection{Saran}

1. Untuk pihak pengelola arung jeram perlunya dibentuk tim penyelamat atau suatu organisasi baik dibentuk oleh stakeholder maupun bekerja sama dengan masyarakat lokal yang bersiaga 
di sepanjang rute arum jeram, serta dalam organisasi tersebut dibentuk beberapa tim yang terbagi di beberapa tempat dalam misi penyelamatan pertama pada atraksi wisata arung jeram.

2. Untuk Bendesa atau pengurus Desa Pekraman Kedewatan perlu lebih rutin

\section{DAFTAR PUSTAKA}

Anonim. Perda Nomer 3 Tahun 2001 Tentang Desa Pekraman. Bali.

Christiani, Brahma Widhi. 2013. Partisipasi Masyarakat Lokal dalam Kegiatan Kepariwisataan di Daya Tarik Wisata Alam Bukit Sari Sangeh Kecamatan Abiansemal Kabupaten Badung. Skripsi. Denpasar:Program Studi S1 Destinasi Pariwisata Fakultas Pariwisata Universitas Udayana.

Dian, Inten, 2006. Kontribusi seni pertunjukkan Kecak Fire sebagai Atraksi Wisata terhadap Kesejahteraan di Desa Adat Padang Tegal, Kecamatan Ubud, Kabupaten Gianyar. Skripsi. Denpasar: Program Studi Pariwisata Universitas Udayana.

Kusmayadi,et.al.2000. Metodelogi Penelitian di Bidang Kepariwisataan. Jakarta: PT.Gramedia Pustaka Utama

Mukhtar. 2013. Metode Praktis Penelitian Deskriptif Kualitatif. Jakarta: REFRENSI (GP Press Group).

Moleong, Lexy J.2012. Metode Penelitian Kualitatif,edisi revisi. Bandung : Rosda.

Moleong, Lexy J.2004.Metode Penelitian Kualitatif. Bandung : PT Remaja Rosdakarya

Pitana, I Gede dan Putu G Gayatri. 2005. Sosiologi Pariwisata. Yogyakarta : Andi.

Suarmana, I wayan Restu 2014. Pengelolaan dan Kontribusi Daya Tarik Mandala Suci Wanara Wana Terhadap Masyarakat Desa Padangtegal Kelurahan Ubud. Skripsi. Fakulatas Pariwisata : Universitas Udayana.

Suparno, I Nyoman. 2008. Kontribusi Kecak Srikandhi sebagai Atraksi Wisata di Desa Adat Ubud, Kecamatan Ubud, Kabupaten Ubud. Skripsi, Fakultas Pariwisata :Universitas Udayana.

Sugiyono. 2013. Metode Penelitian Kuantitatif Kualitatif dan $R \& D$. Bandung : Alfabeta

Yoeti, Oka A. 1982. Pengantar Ilmu Kepariwsataan Bandung : Angkasa.

Sumber Website :

bali.bps.go.id/webbeta/website/brs.../brsInd-

20160201131345.pdf dikutip dan disalin 18 Juli 2016 pukul 20.30 wita. menyampaikan informasi tentang lowongan pekerjaan kepada masyarakatnya terutama perusahaan yang ada di Desa Pekraman Kedewatan baik secara langsung seperti rapat di banjar maupun pengumuman tertulis yang diletakkan dibalai banjar. 